\title{
RECUPERAÇÃO DE ANILINA DE MEIO AQUOSO UTILIZANDO SÍLICA MODIFICADA COM LÍQUIDO IÔNICO POR SPE
}

\author{
J. F. DE CONTO ${ }^{1 *}$, M. R. OLIVEIRA ${ }^{1}$, K. V. CAMPOS ${ }^{1}$, M. M. OLIVEIRA ${ }^{1}$, C. C. SANTANA ${ }^{1}$, \\ S. M. S EGUES ${ }^{1}$. \\ ${ }^{1}$ Universidade Tiradentes, Instituto de Tecnologia e Pesquisa, Laboratório de Síntese de Materiais \\ e Cromatografia. Av Murilo Dantas, 300 - Aracaju-SE \\ *e-mail: jfconto@gmail.com
}

\begin{abstract}
RESUMO
A vasta utilização da anilina na indústria química e farmacêutica gera uma grande quantidade de águas residuais que precisam ser tratadas, pois a anilina afeta negativamente tanto a qualidade ambiental como a saúde humana. A quantidade de anilina presente nas águas residuais deve ser conhecida para que não ultrapassem os limites permitidos de descarte em meios coletores. Sendo assim, técnicas analíticas de separação e posterior quantificação deste composto estão sendo estudas, bem como a síntese de novos materiais que apresentam interação seletiva pela anilina. A síntese de materiais híbridos orgânico-inorgânicos, como a sílica modificada com líquidos iônicos é uma alternativa emergente, devido ao fato da matriz porosa de sílica já ser muito utilizada em várias áreas da química e ciência dos materiais e os líquidos iônicos por possuírem características vantajosas frente a outros compostos orgânicos, como por exemplo, a possibilidade de projetá-lo na superfície do material com determinada polaridade. Dentro deste contexto, o objetivo deste trabalho foi sintetizar sílica modificada com líquido iônico bis(trifluormetanosulfonila)imida de 1metilimidazólio $\left(\mathrm{MIMNTf}_{2}^{-}\right.$) para aplicar como fase estacionária no processo de extração em fase sólida de anilina de sistema aquoso. O material sintetizado apresentou área superficial de $94 \mathrm{~m}^{2} \mathrm{~g}^{-1}$ Através do infravermelho foi possível observar bandas especificas da parte inorgânica e orgânica do material. A análise elementar $\mathrm{CHN}$ confirmou a presença do grupo orgânico devido a percentagem de carbono e nitrogênio presente na amostra. Ao final do processo de SPE verificou-se que quanto menor a concentração de anilina presente na solução aquosa maior a sua recuperação.
\end{abstract}

\section{INTRODUÇÃO}

A anilina é um composto aromático nitrogenado amplamente utilizado como matéria prima na indústria química e farmacêutica. Existem mais de 150 tipos de produtos derivados de anilina, dentre eles pode-se destacar as tintas, plásticos, pesticidas e corantes (QI et al., 2002). A vasta utilização da anilina na indústria química e farmacêutica gera uma grande quantidade de águas residuais que precisam ser tratadas, pois a anilina afeta negativamente tanto a qualidade ambiental como a saúde humana, devido ao efeito cumulativo no meio ambiente e a alta toxicidade (AL-JOHANI e SALAM, 2011).

Os tratamentos tradicionalmente aplicados à decomposição ou remoção da anilina de águas residuais são a eletrólise (HAN et al., 2006), adsorção (VILLACANAS et al., 2006; LÁSZLÓ, 2005), oxidação (JAGTAP e RAMASWAMY, 2006; GOMES et al., 2005), biodegradação (WANG et al., 2007), entre outros (AL-JOHANI e SALAM, 2011). Contudo, esses processos conseguem remover e decompor a anilina até certa concentração, isso porque a anilina é difícil de ser 
decomposta completamente (QI et al., 2002). Desta forma, é evidente que após os tratamentos de águas residuais uma determinada quantidade de anilina ainda estará presente e esta concentração precisa ser conhecida, pois existem limitações nas quantidades de anilina que podem ser descartadas no meio ambiente, tanto aquático como no solo.

Desta forma faz-se necessário estabelecer uma metodologia analítica simples, rápida e ambientalmente correta de separação, pré-concentração e determinação de anilina presente nas águas residuais que serão lançadas no corpo receptor. Uma metodologia analítica amplamente utilizada para este fim é a extração líquido-líquido, entretanto essa metodologia não é ambientalmente correta e apresenta custo elevado, pois grandes quantidades de solventes são utilizadas (VOGEL, 2008). Apesar disso, vários autores utilizam esta técnica empregando líquidos iônicos devido às vantagens que estes solventes apresentam como: a não volatilidade, baixa viscosidade relativa, alta condutividade elétrica, estabilidade térmica, entre outras (SU et al., 2014).

Uma forma de utilizar os líquidos iônicos em uma metodologia analítica de separação e pré-concentração que, diferentemente da extração líquido-líquido, emprega pequenas quantidades de solvente é imobilizando-os na superfície de uma matriz sólida. Embora imobilizados em substratos, as suas propriedades físicas e químicas são mantidas, ou seja, a sua polaridade, estabilidade térmica, baixa volatilidade, e a capacidade de extração não mudam (SU et al., 2014). Assim, estas matrizes sólidas modificadas com líquido iônico podem ser utilizadas como fase estacionária no processo de extração em fase sólida (SPE), já que este método pode substituir a extração líquidolíquido e ainda apresentar vantagens como menor consumo de solventes e tempo experimental reduzido (ALZAGA et al., 2004; ABHILASH, et al., 2007).

Dentro deste contexto, este trabalho visou empregar sílica modificada com líquido iônico, na remoção de anilina de meio aquoso utilizando o processo de SPE.

\section{EXPERIMENTAL}

\subsection{Síntese do material híbrido bis(trifluormetanosulfonila)imida de 1- metilimidazólio por método convencional}

O material híbrido sílica modificada com bis(trifluormetanosulfonila)imida de 1metilimidazólio, designado como $\mathrm{SiNTf}_{2}^{-}$, foi preparado em três etapas.

Na primeira etapa foi feita a síntese da matriz pelo o método sol-gel de acordo com o trabalho de MENEZES et al., (2012) e DE CONTO et al., (2014). Nessa etapa foi utilizado como reagentes precursores tetraetilortosilicato (TEOS) e 3cloropropiltrimetoxisilano (CPTMS), ambos da marca Aldrich, nas proporções molares de 90\% (50,0 mL) de TEOS, $10 \%(4,5 \mathrm{~mL})$ de CPTMS e ácido fluorídrico (HF) da Merck como catalisador. Primeiramente, foi realizada a pré-hidrólise do TEOS pela adição de $80 \mathrm{~mL}$ de etanol e $8 \mathrm{~mL}$ de água destilada sendo esta mistura agitada por $40 \mathrm{~min}$. Após o período de pré-hidrólise, adicionou-se CPTMS e 8,0 mL de água destilada contendo 16 gotas de HF. A mistura foi mantida sob agitação por 40 min a temperatura ambiente, seguido do aumento da temperatura para $40^{\circ} \mathrm{C}$. A gelificação durou 12 dias a esta temperatura, mantida por banho de areia em placa de aquecimento. Ao final do processo o material obtido foi macerado, lavado através da extração soxhlet com etanol por $24 \mathrm{~h}$ e seco em estufa a $80^{\circ} \mathrm{C}$ por $24 \mathrm{~h}$.

$\mathrm{Na}$ segunda etapa realizou-se a reação de ancoramento do 1-metilimidazólio (Aldrich): $10 \mathrm{~g}$ do material obtido na primeira etapa foram imersos em $100 \mathrm{~mL}$ de solução 
de 1-metilimidazólio em tolueno $\left(2,5 \mathrm{~mol} \mathrm{~L}^{-1}\right)$ e aquecida na temperatura de refluxo durante 48 h. O sólido resultante foi separado, lavado com tolueno, etanol, éter etílico e seco em estufa a $80{ }^{\circ} \mathrm{C}$ por $24 \mathrm{~h}$.

E por fim, na terceira etapa foi realizada a troca do ânion $\mathrm{Cl}^{-}$pelo ânion $\mathrm{NTf}_{2}{ }^{-} \cdot \mathrm{Na}$ troca do ânion, uma solução aquosa de bis(trifluormetanosulfonila) imida de lítio (Aldrich) foi utilizada como trocador iônico. As proporções utilizadas foram $2 \mathrm{mmol} \mathrm{de}$ bis(trifluormetanosulfonila)imida de lítio para cada grama do material $\mathrm{SiNTf}_{2}{ }^{-}$. A mistura foi agitada por $24 \mathrm{~h}$ a temperatura ambiente. Posteriormente, o sólido foi separado por filtração a vácuo, lavado com água Mili-q e seco em estufa por $24 \mathrm{~h}$ a $80{ }^{\circ} \mathrm{C}$.

\subsection{Caracterizações}

A área superficial específica (SB.E.T.) e a distribuição do volume de poro foram determinadas por adsorção/dessorção de $\mathrm{N}_{2}$ utilizando o equipamento Micromeritics 3020 Krypton, empregando o método B.E.T. e modelo B.J.H. (multipontos). Anteriormente à análise, as amostras foram tratadas no próprio equipamento a $120{ }^{\circ} \mathrm{C}$, sob vácuo, por $10 \mathrm{~h}$, a fim de eliminar resíduos de umidade ou orgânicos líquidos.

Para a análise de infravermelho utilizou-se um espectrofotômetro com transformada de Fourier Varian FTIR 600, na região de 4000 a $400 \mathrm{~cm}^{-1}$, com resolução de $4 \mathrm{~cm}^{-1}$ e 140 acumulações. Utilizaram-se pastilhas preparadas a partir da dispersão dos sólidos em $\mathrm{KBr}$, na proporção de 1:100 e as análises foram feitas em temperatura ambiente.

A análise elementar foi realizada em um equipamento LECO CHN628 usando uma massa de amostra de $150 \mathrm{mg}$.

\subsection{Curva de calibração e metodologia de análise da anilina}

Para avaliar a eficiência da fase estacionária no processo de SPE, soluções aquosas de anilina foram preparadas nas concentrações de 10,25 e $50 \mathrm{mg} \mathrm{L}^{-1}$.

As curvas de calibração foram obtidas a partir de 5 diferentes concentrações conforme apresentado na Tabela 1. As soluções padrões de anilina (Vetec P.A.) foram preparadas em dois diferentes solventes: água destilada e acetonitrila (Vetec P.A.). Para a obtenção da curva de calibração da anilina utilizou-se um espectrofotômetro de UV-Vis modelo UV2600 da marca Shimadzu. Previamente foi feita uma varredura no espectrofotômetro para determinar o comprimento de onda de maior absorção para o composto.

Tabela 1 - Concentração da solução de anilina em água e acetonitrila.

\begin{tabular}{cc}
\hline \multicolumn{2}{c}{ Concentração de Anilina $\left(\mathrm{mg} \mathrm{L}^{-1}\right)$} \\
\hline Água & Acetonitrila \\
\hline 10 & 5 \\
30 & 10 \\
50 & 20 \\
70 & 30 \\
100 & 40 \\
\hline
\end{tabular}

Após a realização da curva de calibração da anilina tanto em água como em acetonitrila, foram feitas as análises das amostras obtidas na extração em fase sólida (SPE). Foram analisadas as soluções aquosas que continham a anilina antes e após a SPE, para avaliar recuperação.

\subsection{Extração em fase sólida}

O sistema de extração em fase sólida consiste em um recipiente de vidro acoplado a uma bomba de vácuo, para controle do fluxo dos solventes que passam pelo cartucho. A tampa do recipiente contém orifícios onde os cartuchos são encaixados. A coleta da amostra é feita em tubos de ensaio que são colocados dentro do recipiente de vidro.

Os cartuchos de SPE foram empacotados com $500 \mathrm{mg}$ de fase estacionária $\mathrm{SiNTf}_{2}{ }^{-}$e condicionados com $5 \mathrm{~mL}$ de água destilada. Em seguida $10 \mathrm{~mL}$ da amostra foi eluída através da coluna, e posteriormente 
lavadas com $10 \mathrm{~mL}$ de água destilada para remoção dos interferentes. A recuperação da anilina foi realizada através da eluição com 10 $\mathrm{mL}$ de acetonitrila.

\section{RESULTADOS E DISCUSSÃO}

\subsection{Caracterizações}

\subsubsection{Adsorção/dessorção de $\mathrm{N}_{2}$}

A área superficial e o volume de poro do material $\operatorname{SiNTf}_{2}^{-}$foi de $94 \mathrm{~m}^{2} \mathrm{~g}^{-1}$ e 0,256 $\mathrm{cm}^{3} \mathrm{~g}^{-1}$, respectivamente.

\subsubsection{Análise elementar (CHN)}

Verificou-se através da análise elementar (CHN) que a quantidade de carbono e nitrogênio encontrada na sílica funcionalizada com bis(trifluormetanosulfonila)imida de 1-metilimidazólio utilizando o método convencional foi de $10,57 \%$ para o carbono e $3,77 \%$ para o nitrogênio. Isso comprova a presença do grupo orgânico na matriz de sílica.

\subsubsection{Espectroscopia de infravermelho com} transformada de Fourier (FTIR)

Nota-se na Figura 1 uma banda larga na região de $3500 \mathrm{~cm}^{-1}$, essa banda é referente aos modos de vibração das hidroxilas, provenientes dos grupos $\mathrm{SiO}-\mathrm{H}$ da sílica ou H-OH. A banda na região de $1069 \mathrm{~cm}^{-1}$ corresponde à mistura dos grupos $\mathrm{Si}-\mathrm{O}-\mathrm{Si}$ e Si-O-Si-C (ADAM et al., 2009). Os modos de vibração da ligação $\mathrm{C}-\mathrm{N}$ e $\mathrm{C}-\mathrm{H}$ do anel imidazólio surgem na região de $1560 \mathrm{~cm}^{-1} \mathrm{e}$ $2875 \mathrm{~cm}^{-1}$, respectivamente (CAI et al., 2014).

Além destas bandas, observa-se o surgimento de outra na região de $1269 \mathrm{~cm}^{-1}$, segundo YACOOB et al., 2011, bandas na região entre 1000 e $1400 \mathrm{~cm}^{-1}$ são referentes aos modos de vibração da ligação C-F. Essa banda caracteriza o ânion $\mathrm{NTf}_{2}{ }^{-}$que é composto por duas moléculas de CF3 em sua extremidade.

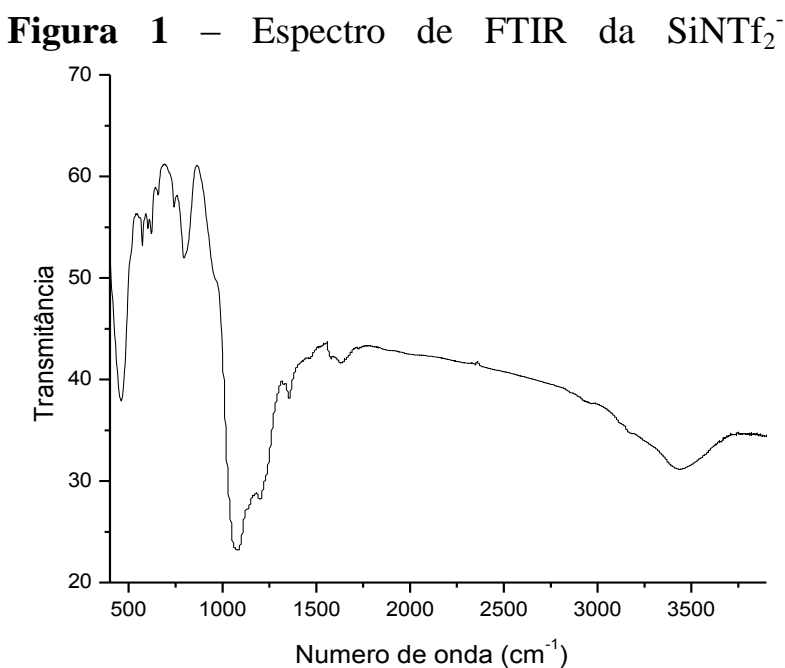

\subsection{Extração em Fase Sólida da Anilina}

Primeiramente foi feito um espectro de varredura para determinar em que comprimento de onda a anilina absorve, esse espectro foi realizado com a solução aquosa de anilina e com a solução de anilina em acetonitrila. Verificou-se que existem três bandas de absorção no espectro de anilina em água e duas bandas de absorção no espectro de anilina em acetonitrila. Dentre as bandas encontradas nas duas amostras, a que foi selecionada para determinação de anilina neste trabalho, e segundo a literatura, são as bandas na região de 280 da anilina em água e $290 \mathrm{~nm}$ para a anilina em acetonitrila (YANG et al., 2011; AL-JOHANI e SALAM, 2011).

Após verificar qual era o comprimento de onda que a anilina absorvia quando preparada em solução aquosa e em acetonitrila, foram feitas as curvas de calibração em ambos os solventes, como mostra a Figura 2. 
Figura 2 - Curva de calibração da anilina em água e em acetonitrila.

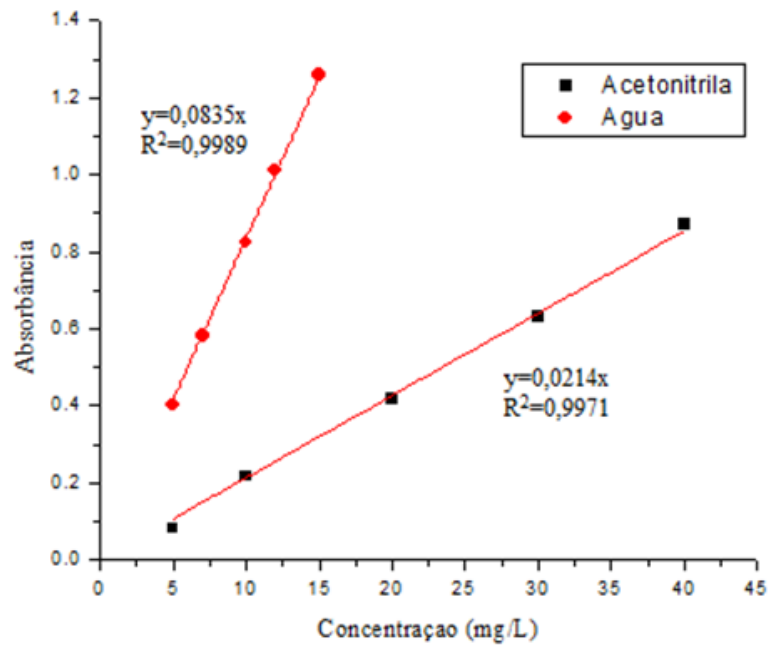

Realizadas as curvas de calibração no espectrofotômetro de UV-Vis e obtidas as equações da reta para cálculo da concentração das amostras, iniciou-se o processo de extração em fase sólida (SPE).

Primeiramente, foi passado pelo cartucho empacotado com a fase bis(trifluormetanosulfonila)imida de 1metilimidazólio (SiNTf2-) a solução aquosa da anilina. Para ter a certeza de que toda a anilina presente na solução aquosa estava retida na fase estacionária, a água da solução foi coletada e analisada após passar pelo cartucho, nas três concentrações iniciais 10, 25 e $50 \mathrm{mg} \mathrm{L}^{-1}$. Os espectros obtidos da solução de anilina após SPE estão apresentados na Figura 3.

Verifica-se nesta Figura que a banda de absorbância na região de 280 nm não aparece para as três amostras nas concentrações iniciais 10,25 e $50 \mathrm{mg} \mathrm{L}^{-1}$, desta forma pode-se afirmar que toda a anilina que estava na solução ficou retida na fase estacionária. Em seguida foi realizada a eluição da mesma com acetonitrila, os resultados estão apresentados na Figura 4.
Figura 3 - Espectro UV-Vis da solução aquosa de anilina após a SPE em três concentrações iniciais diferentes.

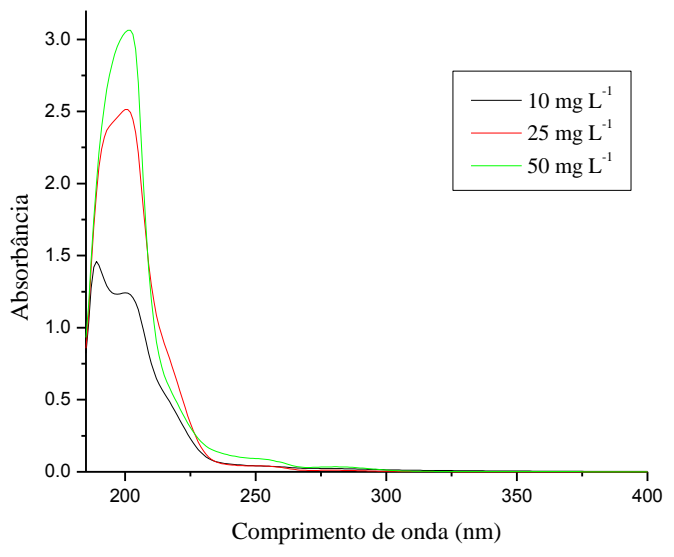

Observa-se na Figura 4 que foi possível recuperar a anilina adsorvida na fase estacionária utilizando como eluente a acetonitrila. Verifica-se também que quanto maior a concentração menor é o percentual removido, ou seja, a recuperação na anilina na concentração de 10,25 e $50 \mathrm{mg} \mathrm{L}^{-1}$ foi de $90,9 \pm 14,21 ; 28,6 \pm 2,11$ e $12,01 \pm 0,20 \%$, respectivamente. A partir destes resultados nota-se que a quantidade de anilina eluída utilizando $10 \mathrm{~mL}$ de acetonitrila foi entre $9 \mathrm{e}$ $6 \mathrm{mg} \mathrm{L}^{-1}$ para todas as concentrações, isso significa que com $10 \mathrm{~mL}$ de acetonitrila é possível remover da fase estacionária concentrações em torno de $8 \mathrm{mg} \mathrm{L}^{-1}$. Entretanto, acredita-se que se o volume de solvente utilizado na eluição for aumentado, as concentrações de anilina recuperada possivelmente serão maiores.

Contudo, observa-se que o processo de SPE utilizando a fase SiNTf $_{2}^{-}$a recuperação da anilina foi melhor em concentrações mais baixas, isto é, quanto mais baixa a concentração inicial da anilina na solução aquosa, melhor a recuperação. No trabalho de CAI et al., 2014, uma membrana polimérica modificada com líquido iônico foi utilizada no processo de micro-extração em fase sólida para a pré-concentração de anilina em solução 
aquosa, segundo os autores a recuperação de

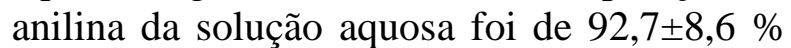
para uma concentração inicial de $10 \mu \mathrm{g} \mathrm{L}^{-1}$. Neste trabalho valores similares de recuperação de anilina foram encontrados, porém, a concentração inicial de anilina na solução aquosa era de $10 \mathrm{mg} \mathrm{L}^{-1}$.

Figura 4 - Percentual de recuperação da anilina utilizando como eluente a acetonitrila.

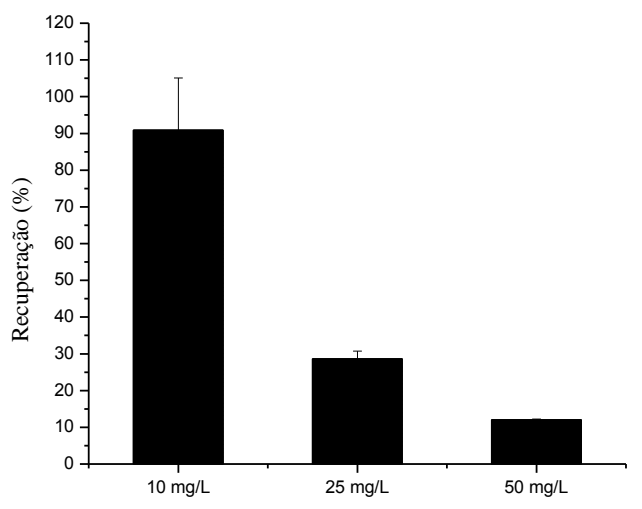

LISSITSYNA et al., 2013 também utilizaram o processo de SPE para a recuperação de anilina de solução oleosa contendo uma mistura de compostos nitrogenados, os autores utilizaram um cartucho com $0,5 \mathrm{~g}$ de sílica e percolaram pelo cartucho $1 \mathrm{~mL}$ da solução contendo anilina e outros compostos nitrogenados, em seguida utilizaram como solvente de eluição da anilina o diclorometano no volume de 9 $\mathrm{mL}$. Ao final do processo os autores verificaram que a recuperação da anilina da solução oleosa nitrogenada foi de 79,1\%.

Sendo assim, verifica-se que o processo de extração em fase sólida pode ser utilizado na separação de anilina de diferentes soluções e a recuperação da anilina tanto neste trabalho como nos demais citados apresentou resultados satisfatórios, principalmente em soluções pouco concentradas.

\section{CONCLUSÃO}

A área superficial e o volume de poro do material SiNTf $_{2}^{-}$foi de $94 \mathrm{~m}^{2} \mathrm{~g}^{-1}$ e 0,256 $\mathrm{cm}^{3} \mathrm{~g}^{-1}$. A quantidade de carbono foi de 10,57 $\%$ e 3,77 \% para o nitrogênio. Isso comprova a presença do grupo orgânico na matriz de sílica. Através do FTIR foi possível observar tanto bandas da parte inorgânica como da parte orgânica do material.

A utilização do material $\operatorname{SiNTf}_{2}^{-}$no processo de remoção e recuperação da anilina foi eficiente, principalmente para baixas concentrações, sendo a remoção da anilina das soluções aquosas da concentração de 10 , 25 e $50 \mathrm{mg} \mathrm{L}^{-1}$ de $100 \%$ e a recuperação de $90,9 \pm 14,21 ; \quad 28,6 \pm 2,11 ; \quad 12,01 \pm 0,20$, respectivamente.

\section{REFERÊNCIAS}

ABHILASH, P.C.; JAMIL, S.; SINGH, N. Matrix solid-phase dispersion extraction versus solid-phase extraction in the analysis of combined residues of hexachlorocyclohexane isomers in plant matrices. Journal of Chromatography A, v. 1176, p. 43-47, 2007.

AL-JOHANI, H.; SALAM, M. A. Kinetics and thermodynamic study of aniline adsorption by multi-walled carbon nanotubes from aqueous solution. Journal of Colloid and Interface Science, v. 360, p. 760-767, 2011.

ALZAGA, R.; MONTUORI, P.; ORTIZ, L.; BAYONA, J.M.; ALBAIGÉS, J. Fast solidphase extraction-gas chromatography-mass spectrometry procedure for oil fingerprinting application to the prestige oil spill. Journal of Chromatography A, v. 1025, p. 133-138, 2004. 
ADAM, F.; OSMAN, H.; HELLO, K.M. The immobilization of 3(chloropropyl)triethoxysilane onto silica by a simple one-pot synthesis. Journal of Colloid and Interface Science, v. 331, p. 143-147, 2009.

CAI, M.; WEI, X.; DU, C.; MA, X.; JIN, M. Novel amphiphilic polymeric ionic liquidsolid phasemicro-extraction membrane for the preconcentration of aniline asdegradation product of azo dye Orange $G$ under sonication by liquidchromatography-tandem mass spectrometry. Journal of Chromatography A, v. 1349, p. 24-29, 2014.

DE CONTO J. F.; SANTOS M. R. O.; CARVALHO A. S.; CAMPOS K. V.; FREITAS L. S.; BENVENUTTI E. V.; DE MENEZES E. W.; SANTANA C. C.; EGUES S. M. Naphthenic acids recovery from petroleum using ionic silica based hybrid material as stationary phase in solid phase extraction (SPE) process. Adsorption, v 20, p. $917-923,2014$.

GOMES, H. T.; SELVAM, P.; DAPURKAR, S. E.; FIGUEIREDO, J. L.; FARIA, J. L. Transition metal ( $\mathrm{Cu}, \mathrm{Cr}$ and $\mathrm{V}$ ) modified MCM-41for the catalytic wet air oxidation of aniline. Microporous and Mesoporous Materials, v. 86, p. 287-294, 2005.

HAN, Y.; QUAN, X.; CHEN, S.; ZHAO, H.; CUI, C.; ZHAO, Y. Electrochemically enhanced adsorption of aniline on activated carbon fibers. Separation and Purification Technology, v. 50, p. 365-372, 2006.

JAGTAP, N.; RAMASWAMY, V. Oxidation of aniline over titania pillared montmorillonite clays. Applied Clay Science, v. 33, p. 89-98, 2006.

LÁSZLÓ, K. Adsorption from aqueous phenol and aniline solutions on activated carbons with different surface chemistry. Colloids and Surfaces A: Physicochemical and Engineering Aspects, v. 265, p. 32-39, 2005.

LISSITSYNA, K.; HUERTAS, S.; QUINTERO, L. C.; POLO, L. M. Novel simple method for quantitation of nitrogen compounds in middle distillates using solid phase extraction and comprehensive twodimensional gas chromatography. Fuel, v. 104, p. 752-757, 2013.

MENEZES, E.W.; LIMA, E.C.; ROYER, B.; DE SOUZA, F.E.; DOS SANTOS, B.D.; GREGÓRIO, J.R.; COSTA, T.M.H.; GUSHIKEM, Y.; BENVENUTTI, E.V. Ionic silica based hybrid material containing the pyridinium group used as an adsorbent for textile dye. J. Colloid Interface Sci, v. 378, p. 10-20, 2012.

QI, X.; ZHUANG, Y.; YUAN, Y.; GU, W. Decomposition of aniline in supercritical water, Journal of Hazardous Materials B, v. 90, p. 51-62, 2002.

SU, P.; WANG, R.; YU, Y.; YANG, Y. Microwave-assisted synthesis of ionic liquid modified silica as a sorbent for the solidphase extraction of phenolic compounds from water. Anal. Methods, v. 6, p. 704 - 709, 2014.

VILLACANAS, F.; PEREIRA, M. F. R.; ORFAO, J. J. M.; FIGUEIREDO, J. L. Adsorption of simple aromatic compounds on activated carbons. Journal of Colloid and Interface Science, v. 293, p. 128-136, 2006.

VOGEL, A.I. Análise química quantitative. 6 ed, Rio de Janeiro, LTC, 2008.

WANG, L.; BARRINGTON, S.; KIM, J. W.; Biodegradation of pentyl amine and aniline from petrochemical wastewater. Journal of 
Environmental Management, v. 83, p. 191197, 2007.

YAACOB, Z.; NORDIN, N. A. M.; YARMO, M. A. Ionic liquid supported acid-catalysed esterification of lauric acid. The Malaysian Journal of Analytical Sciences, v. 15, p. 46 $-53,2011$.

YANG, X.; GUAN, Q.; LI, W. Effect of template in MCM-41 on the adsorption of aniline from aqueous solution. Journal of Environmental Management, v. 92, p. 2939 $-2943,2011$.

\section{AGRADECIMENTOS}

A CAPES, CNPq e FAPITEC pelo apoio financeiro.

Ao Professor Edilson Benvenutti da UFRGS, a Professora Simoni Plentz Meneghetti da UFAL e ao Professor Alberto Wisniewski Jr da UFS e aos seus respectivos grupos de trabalho pela ajuda na caracterização dos materiais. 